\title{
Is OPEC a Cartel? Evidence from Cointegration and Causality Tests
}

\author{
S. Gürcan Gülen \\ Department of Economics \\ Boston College \\ Chestnut Hill, MA 02167 \\ May 1996
}

\begin{abstract}
The energy shocks of the 1970's had significant effects on the global economy. Were they engineered by an effective cartel of OPEC members acting to share the market by controlling output and influencing market prices? If OPEC was an effective cartel sharing the market among its members, there would be a long-run relationship between each member's individual production and total OPEC output. One would also expect OPEC's production to significantly affect the market price of oil as the organization is often accused of curbing production in order to raise prices. These implications of cartel behavior are tested via cointegration and causality tests. The likely effects of regime changes are dealt with using techniques developed by Perron (1989). There is evidence of output coordination among some members of the organization, especially in the output rationing era (1982-93). This is also the only period in which the causality from OPEC production to the price of oil is statistically significant. Overall, the evidence suggests that OPEC did act as a cartel in the 1980 's in order to maintain prices, while it simply took advantage of market conditions in the 1970's and did not have to restrain output.
\end{abstract}




\section{Introduction}

One would expect a cartel to curb production in order to raise the price of its product as well as to share the market among its members. The Organization of Petroleum Exporting Countries (OPEC) is certainly not an exception, as the organization is conventionally referred to as a cartel and blamed for the quadrupling of crude oil prices in 1974. However, OPEC was not able to prevent prices from falling in the 1980 s, even after it adopted output rationing in 1982. This raised the question of whether OPEC was ever able to increase the market price of oil by curbing its production, or whether the organization simply took advantage of high prices caused by political problems and conflicts between some members.

This paper will try to determine whether OPEC is a cartel whose members agree on their role assigned by the organization in an output rationing framework, and whether OPEC has the power of affecting the market price of oil by adjusting its production. These implications of cartel behavior are tested via cointegration (Granger, 1986 and Engle and Granger, 1987) and causality (Granger, 1969, 1980; Geweke, Meese and Dent, 1983) tests: time series techniques rarely used in energy economics. Libecap (1989), in his study of the interstate oil cartel of the 1933-72 period, tested swing producer behavior of the state of Texas by using cointegration tests. He argued that this behavior implies a long-term relationship between Texas output and U.S. market demand, and that these two series should be cointegrated. Dahl and Yücel (1991), considering OPEC, argued that such a longrun relationship could be implied by market-sharing (cartel) behavior, as well. They conducted cointegration tests on two kinds of pairs: i) individual production of a member and total OPEC output, and ii) individual production of a member and output by the rest of OPEC. For the first case, Algeria was the only member that seemed to follow the cartel's 
movements and for the second they found no cointegrating pairs. Overall they rejected cooperative behavior by OPEC members.

In this study, I repeat the first test of Dahl and Yücel, i.e., test for cointegration between each member's output and total OPEC production. However, as compared to their quarterly data which spanned a shorter period of time and excluded some members, ${ }^{1}$ monthly series for all 13 members from January 1965 to February 1993 are used. In addition to improving the performance of the tests involved due to the increased number of observations, this sample covers all the major events of the oil market and allows us to compare the behavior of OPEC and its members before and after the 1973-4 period, as well as during the quota era. In addition, causality tests are employed in order to decide whether OPEC has been able to push prices up by curbing its production and whether nonOPEC producers have been mere price-takers. In both analyses, OPEC is replaced by Saudi Arabia to see whether the Kingdom is the real price-setter and the organization is of no importance.

In order to carry out cointegration and causality tests efficiently, the time series characteristics of the series involved must be analyzed. For example, if these series contain seasonal factors, which is a reasonable possibility for oil production, it would not be possible to distinguish between seasonality and cartel behavior as the reason of the long-run equilibrium relationship. Also, the nature of any trend function should be established and its effects should be taken into account while carrying out the tests. Especially in this case, structural breaks in the trend function are very important and unit root tests (accordingly

1 The data of Dahl and Yücel are from 1971:1 to 1982:4 for Libya, from 1972:1 to 1987:4 for the U.A.E. and 1971:1 to 1987:4 for the rest of OPEC, except for Gabon, Qatar and Ecuador that were excluded from their analysis due to missing data problems. 
cointegration tests) should be modified to incorporate these breaks. The likely effects of these regime changes are dealt with using techniques developed by Perron (1989).

In testing for cointegration between the pairs consisting of individual production levels and total OPEC production, the results might be difficult to interpret if one finds some but not all of the pairs to be cointegrated. Especially if one is interested in overall success of the cartel, a cointegration test among the production levels of all of the members is probably more appropriate. This will allow one to conclude whether the members coordinated their production according to the cartel's movements, perhaps not based on a constant share rule but otherwise. For that purpose, I will use a procedure introduced by Johansen (1988) and Johansen and Juselius (1990) which provides estimation of all possible cointegrating vectors. In fact, as Johansen (1988) pointed out if there are $\mathrm{n}$ variables, it is possible to have up to (n-1) cointegrating vectors.

The results from cointegration tests indicate that although there are some members who coordinate their production with that of OPEC (most apparently the U.A.E., Venezuela and Libya), the organization does not seem to act as a cohesive whole. In particular, Saudi production is not cointegrated with OPEC output in any time period considered, which is probably due to the swing producer role the Kingdom has played in the organization. However, one cannot reject that the production series of seven countries (Algeria, Gabon, Indonesia, Iran, Saudi Arabia, the U.A.E. and Venezuela) are cointegrated in a multivariate setting when the 1982-93 period is considered. This is also the only period in which the causality from OPEC production to the market price of oil is statistically significant. This evidence leads one to believe that despite all the widely publicized incidents of quota negotiations and cheating, and prices that are much lower in the average than the prices in the 1970s, OPEC has been able to strengthen its influence on the market after it officially adopted an output rationing framework in 1982. 
The paper is organized as follows: the next section provides a brief survey of recent events that shaped the oil market. In Section III, certain implications of cartel behavior are studied in relation to cointegration and causality concepts. The data, empirical tests and the results of the tests are presented in Section IV. Section V summarizes the main conclusions of the paper.

\section{Recent History of the World Oil Market}

OPEC is conventionally referred to as a cartel. The unexpected four-fold increase in crude oil prices in the 1973-74 period has been widely considered as a result of collusive behavior of OPEC members. After 1982, OPEC started to act more like a textbook cartel when it adopted output rationing, albeit without a detection and punishment device. However, the organization continued to announce the price of oil, as well; some members failed (or did not want) to obey their quota, as the production ceiling set for collective OPEC output is often violated despite Saudi Arabia's efforts to sustain it. In 1985-6, the price of oil dropped from about $\$ 28$ to below $\$ 12$ per barrel. Although prices recovered to a range of $\$ 17$ to $\$ 19$ per barrel by 1987 and actually jumped over $\$ 30$ mark after the invasion of Kuwait by Iraq, in late 1993 they plunged back below $\$ 15$ per barrel despite repetitive meetings of OPEC (see Figure 1).

The failure of the organization to prevent prices from falling, especially in the output rationing era, raised the question of whether OPEC is capable of regulating production among its members in its effort to control the market price of oil. On the other hand, the 1980s witnessed a substantial decline in the demand for oil by industrialized countries, which carried out energy conservation programs and substituted coal and nuclear energy for oil wherever they could, and an increasing supply by non-OPEC producers. In Figure 2, one can see the increase in non-OPEC supply along with the decline in OPEC production in the 
early 1980s. These developments, mainly the response of the industrialized world to the 1979-80 shock, put a lot of pressure on the cartel as some members started regularly ignoring their quota. Still, the price of oil stayed much higher than the competitive price, which is around $\$ 5$ for Gulf producers and $\$ 8$ for the U.S. according to Adelman (1986).

The political problems of the early 1970s, the Arab-Israeli conflict and the accompanying oil embargo to the West by Arab producers preceded the first oil shock. Late in the decade, the revolution in Iran and the beginning of the Iran-Iraq war were followed by a second shock. The invasion of Kuwait by Iraq in 1990 had similar impacts, but to a smaller extent. Some consider these events as purely political and exogenous to the oil market and believe they are the reason for price increases (e.g., see MacAvoy, 1982). It is apparent from Figures 1 and 2 that each increase in the price is matched with a considerable decline in OPEC production, but one can also see that there are other instances where output by the organization's members decreased without a substantial change in the price. Others believe that some big producers such as Saudi Arabia deliberately refused to increase their production in order to fully compensate for the production loss during those events, which they were capable of, and thus caused prices to rise (e.g., see Adelman, 1990). Figure 2 shows that Saudi production did not increase as much as the loss by the rest of OPEC in either 1979-80 or in 1990. Actually, the Kingdom's production remained roughly constant while the production by the rest of the organization kept falling during the 1979-82 period. As one can see from the coexistence of these opposing views, it is difficult to distinguish between collusive action on the part of OPEC countries or supply disruptions independent of any cartel behavior as the reason for these increases.

Even in the case of the price collapse of 1986, Saudi Arabia and a few other Gulf producers with more than half of world oil reserves might have realized that the decline in the demand for oil and the increase in the non-OPEC supply would hurt their economy in the 
long-run much more than a decrease in the price of oil would in the short-run. During the 1982-85 period, the organization kept all of the shares constant except for Saudi Arabia's who, as the "swing producer," was supposed to produce the difference between the market demand (or production ceiling set by the cartel, whichever was smaller) and the total production by the rest of the cartel. As the demand kept falling, Saudi production fell to around 2 million barrels a day $(\mathrm{mb} / \mathrm{d})$ from $5 \mathrm{mb} / \mathrm{d}$, its full quota according to the production ceiling. One can see from Figure 2 that Saudi production continually decreased in this period while the others enjoyed higher production levels as compared to previous years. Apparently Saudi Arabia could not afford this swing producer role much longer, as the Kingdom started producing near its quota level in the summer of 1985 and not long after that prices collapsed. ${ }^{2}$

\section{Cointegration, Causality and Cartel Behavior}

As Granger (1986) put it "[a]t the least sophisticated level of economic theory lies the belief that certain pairs of economic variables should not diverge from each other by too great an extent, at least in the long-run." One such pair consists of individual member production and total OPEC output. If OPEC were an effective cartel that coordinated output, its members would produce according to the quota scheme established by the organization.

Then one would not expect a member's individual production level and total OPEC production to move away from each other, at least in the long-run. This, in turn, would imply a long-term equilibrium relationship between that member's production and total OPEC production; in time series terminology these two series should be cointegrated. Let the cartel's rule be the following:

2 A recent survey in The Economist (June 18, 1994) seems to agree with this analysis: "OPEC has, it seems, learnt that expensive oil stimulates conservation, alternatives and non-OPEC supplies." 


$$
Q_{i t}=\alpha_{i} Q_{t}
$$

where $Q_{i t}$ is the ith member's and $Q_{t}$ is the total OPEC production at time t, and $\alpha_{i}$ is the production share of the ith member of the cartel. In regular meetings, the organization sets a ceiling for $Q_{t}$ and assigns each member a certain percentage of that amount ( $\alpha_{i}$ as the ith member's quota). Although there are fierce negotiations on how to allocate that amount among the members, it is believed by industry analysts that most of the members are allowed to produce close to their maximum capacity, and countries, such as Saudi Arabia, which have the extra capacity are not likely to exceed their quota (The Wall Street Journal, September 30,1993). Whether this recent trend was also the case in the early days of the output rationing era is ambiguous. However, there is no reason to substantially change the quota of a member unless there is a significant change in their production capacity. Figure 3 presents the realised production shares of OPEC members. Except for Saudi Arabia, Iran, Iraq, Nigeria and Indonesia, the shares seem to remain roughly constant, especially after the mid-1970s. It is obvious that the swing producer role of Saudi Arabia, the revolution in Iran and the Iran-Iraq war are the respective reasons for these countries' shares to fluctuate over time. However, a similar explanation does not exist for Nigeria and Indonesia.

In the framework of equation (1), if the member follows its quota, the long-run relationship between $Q_{i t}$ and $Q_{t}$ will be characterized by the cointegrating vector $\left[1,-\alpha_{i}\right]$. If the member cheats on occasion, an effective cartel should be able to detect and punish the cheating. Hence one can see these diversions from equilibrium as short-run and therefore the long-run relationship should persist. Hence the rejection of cointegration between a member's production level and total OPEC production might imply a lack of coordination between that member and the organization, or consistent cheating by that member and the ineffectiveness of the cartel in terms of detecting and punishing the cheating. 
The main purpose of forming a cartel is to exercise market power by pushing prices higher than they would be under market conditions and thus to reap profits. OPEC is often accused of curbing its production in order to raise prices. OPEC countries own a high percentage of world oil reserves (69.8\% in 1973 and $77.6 \%$ in 1992) and they supply almost half of world crude oil (56\% in 1973 and $40.6 \%$ in 1992). ${ }^{3}$ It appears that they have the power to influence market conditions and the decrease in their share of production along with the increase in their share of reserves is consistent with cartel behavior. Even in 1986, Saudi Arabia might have increased its production in order to lower prices so that there would still be demand for its oil in the long-run. Although not an action one would expect from a textbook cartel, this is an economically sound decision if members want to enjoy high profits for a longer period of time, preferably for the lifetime of their reserves. As the owner of the largest oil reserves in the world these countries should prefer to give up short-run profits in order to guarantee their future profits.

If OPEC (or a certain cartel core) has really been able to affect prices by decreasing (or increasing) its production, this can empirically be detected by using causality tests; there should be causality from OPEC production to the market price of oil and not in the other direction. If the producer country has a revenue absorption constraint, as in the target revenue models (Teece, 1982 and Cremer and Salehi-Isfahani, 1980, 1989), causality from price to production is plausible. However, although some members might have such constraints, OPEC as a whole is not expected to be constrained in that manner. Also there should be causality from the price to non-OPEC production since non-OPEC nations are all price-taking members of the 'competitive fringe.' Again, causality in the other direction is not allowed as the 'competitive fringe' production is not expected to have an effect on the market price of oil.

3 Figures in parentheses are calculated from the data published in Oil and Gas Journal. 


\section{Empirical Analysis}

\section{A. Data}

The data for the monthly production levels (in 1,000 b/d) of thirteen OPEC members are taken from Oil and Gas Journal for the period of January 1965 to February 1993. The Oil and Gas Journal Energy Database is the source for the West Texas Intermediate (WTI) crude oil price (in U.S. dollars per barrel). ${ }^{4}$ Three different price indices for U.S. are used to obtain real values of the oil price: the Consumer Price Index, the Producer Price Index, and the Wholesale Price Index. These series are taken from International Financial Statistics (IFS) database.

\section{B. Testing Procedure}

\section{i. Unit Root Tests}

In order to carry out cointegration tests, the nonstationarity of the series involved must first be established. The first step is to test the null hypothesis that each series is integrated of order one (denoted I(1)), i.e., they each possess a unit root. However, conventional unit root tests are not appropriate in the case of the oil market. As Perron (1989) showed, both analytically and empirically, structural breaks in stationary time series might induce apparent unit roots. Unit root tests lose power when applied to series with trend breaks. Perron developed three models allowing for a one-time change in the level or in the slope of the trend function (or in both) and then calculated critical values for unit root

\footnotetext{
4 The other two price series commonly referred to as representatives of the market price, North Sea Brent and OPEC basket, are highly correlated with WTI. Both usually lag behind WTI, Brent by $\$ 1$ and OPEC basket by $\$ 2$. Monthly price series for Middle Eastern crudes covering the sample period are not available. However, the correlation between S.A. Light, for which monthly data is available after the mid-1970s, and WTI is quite high (around .93). Moreover, these two series have the same structural breaks.
} 
tests under each of these three different data generating processes. In each case critical values are provided for nine different values of the "break fraction" (.1 to .9), i.e., time of break relative to total sample size, $\lambda=T_{B} / T$, where $T_{B}$ is the time of the break and $T$ is the total sample size. He also showed that most macroeconomic time series are not characterized by a unit root as Nelson and Plosser (1982) reported, but rather are stationary around a trend with a single break. The breaks Perron considered were the Great Crash of 1929 and the Oil Shock of 1973. He did not consider two breaks at the same time, probably because data sets used in his examples did not cover both events. However, when one deals with the individual oil production series of OPEC members (or the price of crude oil), unlike most macroeconomic series, there is more than one break in the trend function for most of the series. In addition to common breaks of 1973-4, 1979-80, 1985-6, some countries have some other breaks; for example Kuwait and Iraq share one for 1990, while Iran and Iraq share another in 1980. For this reason, Perron's approach has been extended to incorporate more than one break and critical values are calculated via Monte Carlo methods. 5 Specifically, the following equations are estimated to test for a unit root.

$$
\begin{aligned}
& \Delta x_{t}=\alpha+\delta t+\theta^{\prime} D U_{t}+d^{\prime} D(T B)_{t}+\beta x_{t-1}+\sum_{j=1}^{p} \psi_{j} \Delta x_{t-j}+\varepsilon_{t} \\
& \Delta x_{t}=\alpha+\delta t+\phi^{\prime} D T_{t}^{*}+d^{\prime} D(T B)_{t}+\beta x_{t-1}+\sum_{j=1}^{p} \psi_{j} \Delta x_{t-j}+\varepsilon_{t} \\
& \Delta x_{t}=\alpha+\delta t+\theta^{\prime} D U_{t}+\phi^{\prime} D T_{t}+d^{\prime} D(T B)_{t}+\beta x_{t-1}+\sum_{j=1}^{p} \psi_{j} \Delta x_{t-j}+\varepsilon_{t}
\end{aligned}
$$

where $\quad D U_{t}=1$ if $\mathrm{t}>T_{B}, 0$ otherwise;

5 See page 1364 of Perron (1989) for the models under the null and alternative hypotheses; those under the null are used to generate the data for Monte Carlo runs (whichever model is appropriate for the specific country for which the unit root test is carried out); the ones under the alternative are used for actual tests (equations (2a)-(2c) in this paper). 


$$
\begin{aligned}
& D T_{t}^{*}=\mathrm{t}-T_{B} \text { if } \mathrm{t}>T_{B}, \quad 0 \text { otherwise; } \\
& D T_{t}=\mathrm{t} \text { if } \mathrm{t}>T_{B}, \quad 0 \text { otherwise; } \\
& D(T B)_{t}=1 \text { if } \mathrm{t}=T_{B}+1, \quad 0 \text { otherwise; }
\end{aligned}
$$

and $p$ is selected in order to render $\varepsilon_{t}$ empirically white. The notation for dummies are borrowed from Perron. Here, they represent vectors since more than one break is considered. $T_{B}$ is the vector of break times. $D U_{t}$ represents a change in the level, and $D T_{t}$ (also $D T_{t}^{*}$ ) represents a change in the slope of the trend function. The test statistic is a natural extension of Dickey-Fuller's $(1979,1981)$, i.e., the t-statistic on the OLS estimate of $\beta$. If it is believed there is only change in the level, equation (2a) is used; if the slope of the trend function changes without a change in the level, equation (2b) is appropriate; when there is reason to believe both changes occur, equation (2c) is estimated. If one believes changes do not occur instantaneously $D(T B)_{t}$ must be included (see page 1380 of Perron (1989)).

\section{ii. Cointegration Tests}

\section{Engle and Granger Two Step Procedure}

Two nonstationary series are said to be cointegrated if a stationary linear combination of the two series exists. A particularly interesting case occurs when the nonstationary series are integrated of order one, i.e., they each possess a unit root. If $x_{t}$ and $y_{t}$ are two I(1) series and they are cointegrated, there is a 'cointegrating parameter' $\beta$

such that $z_{t}=x_{t}-\beta y_{t}$ is $\mathrm{I}(0)$, or $z_{t}$ is stationary. This is evidence of a long-run equilibrium relationship between $x_{t}$ and $y_{t}$. Engle and Granger (1987) proposed the following regression for testing cointegration:

$$
x_{t}=\alpha+\beta y_{t}+z_{t}
$$


Then, the residual series $z_{t}$ is tested for a unit root by using the standard Dickey-

Fuller regression:

$$
\Delta z_{t}=\alpha+\delta t+\beta z_{t-1}+\sum_{j=1}^{p} \psi_{j} \Delta z_{t-j}+\varepsilon_{t}
$$

Since $z_{t}$ can be explained as a linear combination of $x_{t}$ and $y_{t}$, both $\mathrm{I}(1)$, if they are cointegrated, the test result should reject the null hypothesis that $z_{t}$ is $\mathrm{I}(1)$. Then $z_{t}$ will be considered to be stationary, satisfying the definition of cointegration. However, the critical values differ from those used in the conventional test procedure. Since the series of interest have structural breaks, they must be detrended. Therefore, instead of $x_{t}$ and $y_{t}$, residuals from the regression of $x_{t}$ and $y_{t}$ on a constant, a time trend and relevant break dummies are used in estimating equation (3). The analogy between the Dickey-Fuller unit root test statistic and its cointegration test counterpart as pointed out by Engle and Granger is still valid (i.e., since the least squares estimate of $\beta$ in equation (4) is chosen in order to minimize the residual variance, one can expect to reject the null hypothesis that $z_{t}$ is $\mathrm{I}(1)$ more often than implied by the nominal test size). Also the differences between trend breaks of the two series involved need to be taken into account. Therefore, relevant critical values of cointegration tests for each pair being tested are calculated via Monte Carlo methods.

\section{Johansen Full Information Maximum Likelihood Procedure}

To test for cointegration among more than two variables, Johansen's cointegration procedure is preferred over the method of Engle and Granger for two reasons. First, Johansen's approach involves full-information maximum likelihood estimation that treats all variables in the system as endogenous, avoiding the arbitrary normalization inherent in Engle and Granger's OLS-based method. Second, one can find all existing cointegrating 
vectors in the system by using Johansen's technique, whereas OLS can only locate one cointegrating vector, or may even fail to detect a cointegrating relationship, depending on the choice of regressand.

Johansen bases his analysis on the following vector autoregressive (VAR) model:

$$
X_{t}=\Pi_{1} X_{t-1}+\ldots+\Pi_{k} X_{t-k}+\mu+\varepsilon_{t}, \quad(\mathrm{t}=1, \ldots, \mathrm{T})
$$

where $\varepsilon_{1}, \ldots, \varepsilon_{T}$ are independent p-dimensional Gaussian variables with mean zero and covariance matrix $\Lambda, X_{t}$ is a $(p \times 1)$ random vector and $X_{-k+1}, \ldots, X_{O}$ are fixed. $\Pi_{1}, \ldots, \Pi_{k}$ are ( $p \times p)$ matrices of parameters and $\mu$ is a unit vector. Model (5) can be rewritten in first differences:

$$
\Delta X_{t}=\Gamma_{1} \Delta X_{t-1}+\ldots+\Gamma_{k-1} \Delta X_{t-k+1}+\Pi X_{t-k}+\mu+\varepsilon_{t}
$$

where $\Gamma_{i}=-\left(I-\Pi_{1}-\ldots-\Pi_{i}\right)$ for $\mathrm{i}=1, \ldots, \mathrm{k}-1$ and $\Pi=-\left(I-\Pi_{1}-\ldots-\Pi_{k}\right)$.

The parameter matrix, $\Pi$, contains information about long-run relationships between the variables in the system. If the $\operatorname{rank}(\Pi)=p$, i.e., $\Pi$ is full rank, all variables in $X_{t}$ are stationary. If, on the other hand, $\operatorname{rank}(\Pi)=0$, model (6) corresponds to a VAR in first differences. Finally, if $0<\operatorname{rank}(\Pi)=r<p$, there are $(p \mathrm{x} r)$ matrices $\alpha$ and $\beta$ such that $\Pi=\alpha \beta^{\prime} . \quad \beta$ is the matrix of cointegrating vectors which render $\beta^{\prime} X_{t}$ stationary, even though $X_{t}$ is non-stationary, and $\alpha$ is a matrix of error correction parameters.

Johansen (1988) and Johansen and Juselius (1990) have shown that under the hypothesis that $\Pi=\alpha \beta^{\prime}, \hat{\beta}$, the maximum likelihood estimate of $\beta$, is found by solving the following eigenvalue problem:

$$
\left|\lambda S_{k k}-S_{k 0} S_{O O}^{-1} S_{O k}\right|=0
$$


where $S_{00}$ : the residual moment matrix from the least squares regression of $\Delta X_{t}$ on

$$
\Delta X_{t-1}, \ldots, \Delta X_{t-k+1}, \text { and } 1
$$

$S_{k k}$ : the residual moment matrix from the least squares regression of $X_{t-1}$ on

$$
\Delta X_{t-1}, \ldots, \Delta X_{t-k+1}, \text { and } 1
$$

$S_{O k}:$ the cross-product residual moment matrix.

The eigenvectors corresponding to the $r$ largest, statistically significant eigenvalues constitute $\hat{\beta}$. The number of statistically significant eigenvalues can be found using two different likelihood ratio tests which complement each other. The likelihood ratio test statistic for the null hypothesis $H_{2}(r): \operatorname{rank}(\Pi) \leq r$, against the full-rank alternative $H_{1}$ : $\operatorname{rank}(\Pi)=p$ is:

$$
-2 \ln \left(Q ; H_{2}(r) \mid H_{1}\right)=-T \sum_{i=r+1}^{p} \ln \left(1-\hat{\lambda}_{i}\right)
$$

where $\hat{\lambda}_{r+1}, \ldots, \hat{\lambda}_{p}$ are the (p-r) smallest eigenvalues of the problem (7). Equation (8) is the trace statistic employed to test whether there are at most $r$ cointegrating relationships. The likelihood ratio test statistic for the null hypothesis $H_{2}(r)$, against the alternative $H_{2}(r+1): \operatorname{rank}(\Pi) \leq r+1$ is:

$$
-2 \ln \left(Q ; H_{2}(r) \mid H_{2}(r+1)\right)=-T \ln \left(1-\hat{\lambda}_{r+1}\right)
$$

Equation (9) is the maximum eigenvalue statistic used to test whether there are at most $\mathrm{r}$ or $(\mathrm{r}+1)$ cointegrating relationships. 
iii. Causality Tests

The concept of causality introduced by Granger (1969) is based on the following premise: $x$ is said to Granger-cause $y$ if the forecast of $y$ using past $y$ and past $x$ is better than that which just uses past $y$. Sims (1972) shows that in

$$
x_{t}=\sum_{j=-\infty}^{\infty} \beta_{j} y_{t-j}+\varepsilon_{t}
$$

$\beta_{j}=0$ for all $\mathrm{j}<0$ if and only if $x$ does not Granger-cause $y$. The feasible version of this regression consists of a finite number of leads and lags of $y$ along with current $y$, and testing the null that $x$ does not Granger-cause $y$ reduces to testing the joint significance of the leads of $y .6$

Another version of the test regresses $y$ on lagged $y$ and lagged $x$ and tests for the joint significance of the lags of $x$ (known as the "Granger test"). Geweke, Meese and Dent (1982) found that failure to correct for serial correlation adversely affects the results of the Sims test. They also proposed an alternative method in which $x$ is regressed on past, present, and future $y$ and past $x$, and the leads of $y$ are tested (from here on the GMD test). The Wald variant of the test statistic on the joint significance of the lags of $x$ in the Granger test and of the leads of $y$ in the GMD test are found to be superior to the other six test statistics they considered. Guilkey and Salemi (1982) found similar results: both Granger and GMD tests are superior to the Sims test, especially in small samples, and accurately recover the coefficients of the relevant population projections. Following these suggestions, in this study both Granger and GMD tests are used. Series are detrended by regressing on

6 This test, which is based on simple time series techniques, is justified by the use of the Wold decomposition theorem. For details, see Granger (1969), Sims (1972) and Pierce and Haugh (1977) among others. 
a constant, a time trend and break dummies, and first differences are taken if they have a unit root before being used in causality test regressions. Specifically, the following regressions are estimated:

$$
\begin{aligned}
& y_{t}=\alpha+\sum_{j=1}^{p} \beta_{j} y_{t-j}+\sum_{j=1}^{p} \delta_{j} x_{t-j}+\varepsilon_{t} \\
& x_{t}=\alpha+\sum_{j=-p}^{p} \beta_{j} y_{t-j}+\sum_{j=1}^{p} \delta_{j} x_{t-j}+\varepsilon_{t}
\end{aligned}
$$

where $p$ is the number of lags. In the Granger version (equation (10a)), joint significance of all the lags of $x$ is tested $\left(\mathrm{H}_{0}: \delta_{j}=0\right.$ for all $j$ ), while in the GMD variation (equation (10b)) the null hypothesis being tested is that the leads of $y$ are not jointly significant $\left(\mathrm{H}_{0}: \beta_{j}=0\right.$ for $j=-p, \ldots,-1)$.

C. Results 7

Tests of Section IV-B are carried out for four different time periods: 1965:1-1993:2 (full sample), 1965:1-1973:9 (before the first oil shock), 1974:2-1993:2 (after the first oil shock) and 1982:1-1993:2 (the output rationing era). ${ }^{8}$ This allows us to compare the performance of OPEC before and after the first oil shock of 1973-4, which is conventionally accepted as the time that the OPEC cartel took control, as well as to see whether the

7 All the results reported in this section are from estimations including seasonal dummies, as seasonality may affect the results of the tests carried out in this essay. In that direction, a set of 12 centered (i.e., mean zero) dummies is created and 11 of them are included in equation (2) for unit root tests, in equation (3) for bivariate cointegration tests, in the VAR system (6) for multivariate cointegration tests, and in equations (10a) and (10b) for causality tests.

8 Four months in between the two consecutive periods, October 1973 through January 1974 , are left out of the analysis of these two periods. Almost all of the countries have a break in one of these four months and to have such a break in the first or last observation of the sample does not add more information, but complicates estimation. 
organization has been successful in coordinating output among its members after it adopted the quota system in 1982.9

Tables 1a-1d summarize the results of unit root tests. Along with the test statistics, combination of $\lambda$ 's (break fractions) and corresponding critical values for each country are presented. In most of the cases, equation (2c) is used, because it is reasonable to assume that responses to the shocks did not occur instantaneously. However, this does not necessarily mean that there was a dummy for the level change and another one for the slope change for each break considered. For example in Table 1a, breaks of Iran corresponding to $\lambda=.5$ and .6 are represented by both kind of dummies while that for $\lambda=.3$ is included only as a slope change dummy. The breaks for each series are primarily determined from well-known events (Arab oil embargo, Iran revolution, Iran-Iraq war, etc....) that affected the whole market or the production of individual countries, but specific dates for these breaks are chosen by the graphical analysis of time series data.

For the full sample period (1965:1-1993:2), the results indicate that production series for Algeria, Iran, Iraq, and Qatar are stationary around a trend with structural breaks. The null hypothesis of a unit root is rejected for these series even at the $1 \%$ significance level (Table 1a). For the 1965:1-1973:9 period, the null hypothesis of a unit root cannot be rejected for Algeria, Indonesia and Saudi Arabia (only at the 1\% level for the last two). All other countries are considered to be stationary (Table 1b). Gabon, Indonesia, Libya, Nigeria, Saudi Arabia, Algeria, the U.A.E. and Venezuela are the countries for which the production is nonstationary (for the last three the null of a unit root can be rejected at

9 Ecuador, who became a member in 1973, and Gabon, who became an associate member in 1973 and a full member in 1975, are left out of the first two periods. Nigeria (a member since 1971) is excluded from the 1965:1-1973:9 period. Finally, the first two periods start in January 1967 for the U.A.E. and January 1969 for Algeria, their respective dates of entrance to the organization. 
the $5 \%$ but not at the 1\% level) in the 1974:2-1993:2 period (Table 1c). Finally in the quota period (Table 1d), one cannot reject the unit root hypothesis for Algeria, Gabon, Indonesia, Iran, Saudi Arabia, the U.A.E. and Venezuela (again only at the $1 \%$ level for four of them).

Since integration of order one is a precondition for cointegration tests, the series without a unit root are excluded from the cointegration analysis in each of the four periods analyzed.10 The results of pairwise cointegration tests between individual member production and total OPEC production are reported in Table 2a. The test statistic is the OLS estimate of $\beta$ from equation (4) in which the residual series from equation (3) is tested for a unit root.

For Kuwait, Libya, the U.A.E. and Venezuela, the null hypothesis of no cointegration is rejected (but only at the $5 \%$ level for Libya and Venezuela) when the full sample is considered. These countries seem to coordinate their output with that of OPEC. However, for Indonesia, Nigeria and Saudi Arabia this conclusion do not hold, since their production is not cointegrated with total OPEC output (the null of no cointegration cannot be rejected even at the $10 \%$ level). Although Indonesia and to some extent Nigeria are smaller, insignificant members of the organization who might have acted independently, Saudi Arabia is the leader of OPEC by any criterion. The Saudis' seemingly uncooperative behavior is surprising, especially when the co-movement of the other two members of the most conventional cartel core, Kuwait and the U.A.E., is considered. As a check to see whether some countries follow the actions of Saudi Arabia more closely than those of the organization, OPEC output is replaced by Saudi production (Table 2b). Except for Nigeria and the U.A.E., none of the other countries seem to coordinate their production with that of

10 The 1965:1-1973:9 period is totally excluded from this analysis, as OPEC output is stationary and there are only three countries with nonstationary production (one of them, Algeria, was only a member since 1969). 
the Kingdom, and the null of no cointegration can be rejected only at the $5 \%$ level for the U.A.E.

The results of the full sample nearly duplicate themselves in the 1974:2-1993:2 subperiod. Libya, the U.A.E. and Venezuela, along with Algeria and Nigeria, are the countries which move together with OPEC in the long-run, and Gabon, Indonesia and Saudi Arabia are the countries which do not move in accordance with the organization's policies. Again the results are weak for Libya and Venezuela since one cannot reject the null of no cointegration at the $1 \%$ level. When OPEC output is replaced with Saudi production, Algeria, Libya and Nigeria are found to coordinate their production policies with Saudi Arabia's, but the U.A.E. and Venezuela do not seem to follow Saudi actions as closely as they follow those of the organization. The U.A.E. and Venezuela are the only two countries who seem to have continued to follow OPEC policies closely after 1982, as their production is cointegrated with that of OPEC, as well as that of Saudi Arabia.

It is difficult to interpret these pairwise cointegration test results as we find some but not all of the pairs to be cointegrated. Especially if one is interested in overall cohesion of the members in the long-run, a cointegration test among the production levels of all of the members (or members of a certain cartel core) is probably more appropriate. This will allow one to conclude whether the members coordinated the production levels according to the cartel's (or the core's) actions, perhaps not according to a quota system but in some other manner. To investigate this possibility cointegration among all members is tested using the Johansen technique discussed in Section IV-B. The results are presented in Table 3. For the first two periods there is no cointegrating relationship among the production series of countries included in the analysis. Neither the five members in the 1965:1-1993:2 period nor the eight members in the 1974:2-1993:2 period move together. The same conclusion of no coordination holds for the cartel core of Kuwait, Saudi Arabia and the U.A.E. in the 
1967:1-1993:2 period (adjusted for the U.A.E.'s entrance date). However, the quota period displays different characteristics: there is a cointegrating relationship among the production series of seven OPEC members included in the system. The null of no cointegration $\left(\mathrm{H}_{2}\right.$ : $r=0$ ) can be rejected at the $5 \%$ level by both the trace and $\lambda$ max statistics.

The precondition of a unit root for the series to be included in the cointegration analysis somewhat limited the scope of these tests. Nevertheless there are some apparent conclusions. The U.A.E., Venezuela and to a certain degree Libya tend to move in harmony with the organization; in other words they respect their quota. This might also explain why Saudi production is not cointegrated with that of OPEC. Because of the swing producer role the Kingdom played for a long time, the Saudis did not have a chance to follow their quota. However, the reason for lack of coordination on the part of Gabon and Indonesia is more likely to be cheating. Consistent with these findings, Figure 3 shows that shares of the U.A.E., Venezuela and Libya stayed approximately constant while those of Saudi Arabia and Indonesia fluctuated. Also, despite the fierce negotiations about the allocation of production among the members in OPEC meetings, the widely publicized cheating of some members and the price collapse of 1986, at least seven members of OPEC seem to act as a cohesive whole in the 1982:1-1993:2 period.

Tables $4 \mathrm{a}-4 \mathrm{~b}$ report the results from causality tests. The p-values of the Wald variant of both Granger and GMD tests are reported for both bivariate (OPEC/price, nonOPEC/price) and trivariate (OPEC/non-OPEC/price) systems. ${ }^{11}$ One should be cautious in the bivariate case; it is well known that spurious causality can be found when a relevant

11 For each equation the lag length is determined based on Akaike and Schwarz information criteria (known as AIC and SIC) and also based on whether any serial correlation remains in the equation. For example, if the AIC and/or the SIC indicated an optimal lag length of 3 , but the equation still suffered from serial correlation, a higher lag length which remedied the correlation problem was utilized. 
variable is omitted. Lütkepohl (1982) has shown that non-causality due to omitted variables is also possible.

For the 1965:1-1973:9 period, OPEC production does not Granger-cause the market price of oil (lags of OPEC production are not jointly significant in the price equation (10a), and leads of OPEC production are not jointly significant in the price equation (10b)), and is not Granger-caused by the oil price neither in bivariate nor trivariate systems. When OPEC output is replaced by Saudi production, there is still no statistically significant causal relationship. All of the p-values are higher than 0.18 .

The 1974:2-1993:2 subperiod is not much different than the previous subperiod. Again, there is no statistically significant causal relationship in either direction. Nevertheless one can see that $\mathrm{p}$-values are always lower in the production-to-price direction (with both OPEC and Saudi Arabia) than in the price-to-production direction. In two occasions (both with OPEC), p-value is less than 0.15 for the former, whereas it is always higher than 0.50 for the latter case. It seems that, although OPEC (or Saudi Arabia) has been able to influence the market without any feedback from the price in terms of adjusting their production policies, these effects have not been significant enough to be statistically evident at the conventional test levels. This period seems to dominate the whole sample as the same conclusions prevail overall.

The most interesting results have been obtained from the output coordination era: OPEC output Granger-causes the price of oil without any feedback. This conclusion is supported by both variations of the test in both bivariate and trivariate systems, with all four p-values less than 0.04 .

There is no statistically significant causal relationship between non-OPEC production and the price of oil in either direction, in any period. However, p-values are 
almost always less than 0.20 in the price-to-production direction (lowest among the four periods considered), and the p-value for the GMD test is 0.042 in the trivariate system with Saudi Arabia during the 1982-93 period (Table 4b).

The results of causality tests reported above are quite robust to whether one arbitrarily uses 3, 6, 9 or 12 lags instead of lag length suggested by the AIC and/or the SIC (see footnote 12), and also to whether the real or the nominal price is used. The main conclusions still hold: there is no evidence for causality from OPEC output to the market price of crude oil before the output rationing era, and the evidence is unambiguous for that period.

\section{Conclusion}

If OPEC were an effective cartel sharing the market among its members, there would be a long-run equilibrium relationship between each member's individual production and total OPEC output. This idea is tested using cointegration analysis and some members' production levels are found to move together with that of the organization in the long-run (especially the U.A.E., Venezuela and Libya). Perhaps surprisingly, Saudi Arabia is not one of them. However, this is probably due to the swing producer role the Kingdom played. The most interesting result is that seven members coordinated their production during the 1982-93 period, while such cohesion was not detected in any other period considered.

One would expect a cartel's output to affect the market price of its product. OPEC, especially, has been accused of exercising market power by deliberately reducing its output in order to raise prices. This causal relationship is empirically tested. Again, the 1982-93 period is the only time span during which the organization has been able to affect prices. 
Overall, the evidence favors coordination among the members, especially during the output rationing era. Most analysts consider that OPEC's market power eroded during this period. The price collapse of 1986 is seen as a result of OPEC's failure to manage the quota system. However, our evidence suggests that another explanation is possible: OPEC started to act as a cartel in the 1980s in order to prevent prices from falling further. It is sometimes argued that the high prices of the 1970's were not the result of collusive behavior of OPEC countries; that prices were too low before 1973-4 and an adjustment was needed. But prices increased much more than necessary and the oil market stagnated. The demand for OPEC oil kept falling as other energy sources were substituted for oil, especially in the industrialized countries, and non-OPEC production continued to increase. Neither the loss of market share nor the prospect of lower demand for its oil in the future was acceptable to OPEC, especially to those members in the Persian Gulf who own the largest reserves in the world. In response, members started acting as a cartel in order to maintain prices. 


\section{References:}

Adelman, M.A. "The Competitive Floor to World Oil Prices." The Energy Journal, 7, (1986), $9-31$.

Adelman, M.A. "The 1990 Oil Shock Is Like the Others." The Energy Journal, 11, (1990), 113.

Cremer, J. and D. Salehi-Isfahani. "A Theory of Competitive Pricing in the Oil Market: What Does OPEC Really Do?" CARESS, Philadelphia: University of Pennsylvania, Working Paper \#80-4, (1980).

Cremer, J. and D. Salehi-Isfahani. "The Rise and Fall of Oil Prices: A Competitive View." Annales D'Economie et De Statistique, 15/16, (1989), 427-54.

Dahl, C. and M. Yücel. "Testing Alternative Hypotheses of Oil Producer Behavior." The Energy Journal, 12, (1991), 117-38.

Dickey, D.A. and W.A. Fuller. "Distribution of Estimators for Autoregressive Time Series with a Unit Root." Journal of American Statistical Association, 84, (1979), 427-31.

Dickey, D.A. and W.A. Fuller. "Likelihood Ratio Statistics for Autoregressive Time Series with a Unit Root." Econometrica, 49, (1981), 1057-72.

Engle, R.F. and C.W.J. Granger. "Cointegration and Error Correction: Representation, Estimation and Testing." Econometrica, 55, (1987), 251-76.

Geweke, J., R. Meese and W. Dent. "Comparing Alternative Tests of Causality in Temporal Systems." Journal of Econometrics, 21, (1983), 161-94.

Granger, C.W.J. "Investigating Causal Relations by Econometric Models and Cross-Spectral Methods." Econometrica, 37, (1969), 424-38.

Granger, C.W.J. "Testing for Causality." Journal of Economic Dynamics and Control, 2, (1980), 329-52.

Granger, C.W.J. "Developments in the Study of Cointegrated Economic Variables." Oxford Bulletin of Economics and Statistics, 48, (1986), 213-28. 
Guilkey, D.K. and M.K. Salemi. "Small Sample Properties of Three Tests for GrangerCausal Ordering in a Bivariate Stochastic System." The Review of Economics and Statistics, 68, (1982), 668-80.

Johansen, S. "Statistical Analysis of Cointegrating Vectors." Journal of Economic Dynamics and Control, 12, (1988), 231-54.

Johansen, S. and K. Juselius. "Maximum Likelihood Estimation and Inference on Cointegration - With Applications to the Demand for Money." Oxford Bulletin of Economics and Statistics, 52, (1990), 169-210.

Libecap, G.D. "The Political Economy of Crude Oil Cartelization in the United States, 19331972." The Journal of Economic History, 49, (1989), 833-55.

Lütkepohl, H. "Non-Causality Due to Omitted Variables." Journal of Econometrics, 19, (1982), 367-78.

MacAvoy, P.W. Crude Oil Prices As Determined by OPEC and Market Fundamentals, Cambridge: Ballinger, 1982.

MacKinnon, J.G. "Critical Values for Cointegration Tests." Ch. 13 in Long-run Economic Relationships: Readings in Cointegration (Ed.) R.F. Engle and C.W.J. Granger, Oxford, Oxford University Press, 1991.

Nelson, C.R. and C.I. Plosser. "Trends and Random Walks in Macroeconomic Time Series." Journal of Monetary Economics, (1982), 139-62.

Perron, P. "The Great Crash, the Oil Price Shock, and the Unit Root Hypothesis." Econometrica, 57, (1989), 1361-1401.

Pierce, D.A. and L.D. Haugh. "Causality in Temporal Systems: Characterizations and Survey." Journal of Econometrics, 5, (1977), 265-93.

Sims, C.A. "Money, Income, and Causality." American Economic Review, 62, (1972), 540-52.

Teece, D.J. "OPEC Behavior: An Alternative View." in J.M. Griffin and D. Teece eds., OPEC Behavior and World Oil Prices, London: Allen and Unwin, 1982. 
Table 1a- Unit root test results, 1965:1-1993:2. ${ }^{\text {a }}$

Critical values at $1 \%$,

\begin{tabular}{lcccc} 
Country & \multicolumn{2}{l}{ Test statistic $\mathrm{b}, \mathrm{c}$} & $\lambda$ combinations & $5 \%$ and $10 \%$ \\
\hline Algeria $(1969)$ & -6.69 & {$[1]$} & $(.1, .5)$ & $-5.07,-4.51,-4.19$ \\
Indonesia & -4.51 & {$[7]$} & $(.3, .5, .6)$ & $-5.49,-4.93,-4.64$ \\
Iran & -7.20 & {$[0]$} & $(.3, .5, .6)$ & $-5.37,-4.79,-4.48$ \\
Iraq & -10.48 & {$[0]$} & $(.3, .6, .9)$ & $-5.27,-4.75,-4.43$ \\
Kuwait & -4.56 & {$[1]$} & $(.3, .4, .5, .6, .9)$ & $-5.43,-4.82,-4.51$ \\
Libya & -4.76 & {$[1]$} & $(.2, .3, .5, .6)$ & $-5.83,-5.27,-4.97$ \\
Nigeria (1971) & -4.28 & {$[11]$} & $(.2, .3, .4)$ & $-5.30,-4.69,-4.35$ \\
Qatar & -9.22 & {$[0]$} & $(.3, .6, .8)$ & $-5.14,-4.58,-4.27$ \\
Saudi Arabia & -4.07 & {$[0]$} & $(.3, .5, .6, .7)$ & $-5.59,-4.99,-4.68$ \\
U. A. E. (1967) & -1.35 & {$[7]$} & $(.3, .4, .7)$ & $-4.64,-4.03,-3.69$ \\
Venezuela & -4.01 & {$[0]$} & $(.2, .3, .4, .8)$ & $-5.55,-4.94,-4.64$ \\
Price (WTI) & -7.11 & {$[11]$} & $(.3, .5, .7)$ & $-5.81,-5.26,-4.96$ \\
non-OPEC & -2.59 & {$[2]$} & $(.8)$ & $-4.38,-3.82,-3.50$ \\
OPEC & -4.38 & {$[1]$} & $(.3, .5, .7)$ & $-5.22,-4.62,-4.30$ \\
\hline
\end{tabular}

a Critical values are calculated via Monte Carlo for 500 observations with 10000 replications. Critical values for single break cases are taken from Perron (1989). $\mathrm{b}$ Numbers in squared brackets are the numbers of lagged differences ( $p$ ) used in augmenting the estimated equation.

$\mathrm{c}$ Test statistic is the t-statistic for the OLS estimate of $\beta$ in equation (2). 
Table 1b- Unit root test results, 1965:1-1973:9. a

Critical values at $1 \%$,

\begin{tabular}{lcccc} 
Country & \multicolumn{2}{c}{ Test statistic $\mathrm{b}, \mathrm{c}$} & $\lambda$ combinations & $5 \%$ and $10 \%$ \\
\hline Algeria (1969) & -1.03 & {$[0]$} & $(.5)$ & $-4.90,-4.24,-3.96$ \\
Indonesia & -3.81 & {$[0]$} & & \\
Iran & -7.64 & {$[0]$} & & \\
Iraq & -5.72 & {$[0]$} & & $-4.38,-3.82,-3.50$ \\
Kuwait & -7.77 & {$[0]$} & $(.8)$ & $-4.57,-3.95,-3.66$ \\
Libya & -6.94 & {$[0]$} & $(.6)$ & \\
Qatar & -4.58 & {$[0]$} & & \\
Saudi Arabia & -3.99 & {$[0]$} & & $-4.70,-4.04,-3.69$ \\
U. A. E. (1967) & -6.71 & {$[0]$} & & \\
Venezuela & -5.00 & {$[1]$} & $(.8)$ & \\
Price (WTI) & -2.29 & {$[0]$} & & \\
non-OPEC & -1.79 & {$[1]$} & & \\
OPEC & -6.40 & {$[0]$} & & \\
\hline
\end{tabular}

a Critical values for single break cases are taken from Perron (1989). For series without breaks, the standard Dickey-Fuller procedure is applied. Critical values for those are $-4.05,-3.45$, and -3.15 at the $1 \%, 5 \%$ and $10 \%$ significance level, respectively.

b See Table 1a.

c Test statistic is the t-statistic for the OLS estimate of $\beta$ in equation (2), or equation

(4) in case of no breaks. 
Table 1c- Unit root test results, 1974:2-1993:2. ${ }^{\mathrm{a}}$

Critical values at $1 \%$,

\begin{tabular}{|c|c|c|c|c|}
\hline Country & Test sta & $\mathrm{b}, \mathrm{c}$ & $\lambda$ combinations & $5 \%$ and $10 \%$ \\
\hline Algeria & -4.61 & {$[0]$} & (.4) & $-4.81,-4.22,-3.95$ \\
\hline Ecuador & -12.02 & {$[0]$} & $(.7)$ & $-4.75,-4.18,-3.86$ \\
\hline Gabon & -3.75 & [1] & $(.2, .5, .8)$ & $-4.85,-4.27,-3.97$ \\
\hline Indonesia & -2.89 & {$[2]$} & $(.2, .4)$ & $-4.89,-4.31,-4.02$ \\
\hline Iran & -6.40 & {$[0]$} & $(.2, .3)$ & $-4.92,-4.29,-3.97$ \\
\hline Iraq & -9.11 & {$[0]$} & $(.3, .9)$ & $-5.08,-4.44,-4.14$ \\
\hline Kuwait & -6.60 & {$[0]$} & $(.2, .3, .4, .9)$ & $-4.99,-4.40,-4.04$ \\
\hline Libya & -4.41 & {$[0]$} & $(.3, .4)$ & $-4.96,-4.41,-4.12$ \\
\hline Nigeria & -3.34 & {$[9]$} & $(.2, .3)$ & $-4.92,-4.29,-3.97$ \\
\hline Qatar & -9.25 & {$[0]$} & $(.4, .7)$ & $-4.94,-4.40,-4.09$ \\
\hline Saudi Arabia & -4.11 & {$[0]$} & $(.2, .4, .6)$ & $-5.36,-4.79,-4.48$ \\
\hline U. A. E. & -4.42 & {$[1]$} & $(.2, .6)$ & $-4.50,-3.95,-3.65$ \\
\hline Venezuela & -4.24 & {$[0]$} & $(.1, .7)$ & $-4.64,-4.08,-3.80$ \\
\hline Price (WTI) & -5.76 & {$[5]$} & $(.3, .6)$ & $-5.31,-4.76,-4.47$ \\
\hline non-OPEC & -1.14 & {$[5]$} & $(.7)$ & $-4.51,-3.85,-3.57$ \\
\hline OPEC & -2.93 & {$[3]$} & $(.3, .6)$ & $-4.56,-4.00,-3.70$ \\
\hline
\end{tabular}

a Critical values are calculated via Monte Carlo for 500 observations with 10000 replications. Critical values for single break cases are taken from Perron (1989). b, c See Table 1a. 
Table 1d- Unit root test results, 1982:1-1993:2. ${ }^{\text {a }}$

Critical values at $1 \%$,

\begin{tabular}{lcccc} 
Country & Test statistic $b, \mathrm{c}$ & $\lambda$ combinations & $5 \%$ and $10 \%$ \\
\hline Algeria & -2.84 & {$[0]$} & & \\
Ecuador & -10.03 & {$[0]$} & $(.5)$ & $-4.90,-4.24,-3.96$ \\
Gabon & -3.83 & {$[1]$} & $(.1, .6)$ & $-4.48,-3.88,-3.58$ \\
Indonesia & -3.80 & {$[1]$} & & \\
Iran & -3.83 & {$[5]$} & & \\
Iraq & -5.92 & {$[1]$} & $(.8)$ & $-4.70,-4.04,-3.69$ \\
Kuwait & -6.02 & {$[0]$} & $(.8)$ & $-4.70,-4.04,-3.69$ \\
Libya & -4.16 & {$[0]$} & & \\
Nigeria & -7.54 & {$[1]$} & & \\
Qatar & -6.65 & {$[0]$} & $(.5)$ & $-4.56,-3.96,-3.68$ \\
Saudi Arabia & -2.38 & {$[1]$} & $(.3)$ & $-4.51,-3.87,-3.58$ \\
U. A. E. & -4.32 & {$[2]$} & $(.3)$ & $-4.51,-3.87,-3.58$ \\
Venezuela & -4.48 & {$[0]$} & $(.5)$ & $-4.56,-3.96,-3.68$ \\
Price (WTI) & -5.53 & {$[1]$} & $(.4)$ & $-4.81,-4.22,-3.95$ \\
non-OPEC & -4.29 & {$[1]$} & $(.6)$ & $-4.57,-3.95,-3.66$ \\
OPEC & -3.77 & {$[1]$} & $(.3)$ & $-4.51,-3.87,-3.58$ \\
\hline Critical values & for & & & \\
\hline
\end{tabular}

a Critical values for Gabon are calculated via Monte Carlo for 500 observations with 10000 replications. Critical values for single break cases are taken from Perron (1989).

For series without breaks, the standard Dickey-Fuller procedure is applied. Critical values for those are $-4.05,-3.45$ and -3.15 at the $1 \%, 5 \%$ and $10 \%$ significance level, respectively.

b See Table 1a.

c See Table $1 b$. 
(Tables $2 \mathrm{a}, 2 \mathrm{~b}$ are in a separate document, in landscape format).

Table 3- Multivariate cointegration test results. ${ }^{\text {a }}$

\begin{tabular}{|c|c|c|c|c|}
\hline $\operatorname{trace}(0.95)$ & $\lambda \max (0.95)$ & $\mathrm{H}_{2}$ & trace & $\lambda \max$ \\
\hline \multicolumn{5}{|c|}{ all countries: 1965:1-1993:2 b } \\
\hline 68.61 & 68.61 & $r \leq 4$ & 12.16 & 12.16 \\
\hline 81.81 & 78.01 & $r \leq 3$ & 31.19 & 19.03 \\
\hline 197.46 & 184.97 & $r \leq 2$ & 57.77 & 26.59 \\
\hline 258.94 & 230.94 & $r \leq 1$ & 93.43 & 35.66 \\
\hline 319.22 & 263.80 & $\mathrm{r}=0$ & 142.94 & 49.50 \\
\hline \multicolumn{5}{|c|}{ the cartel core: $1967: 1-1993: 2^{\mathrm{c}}$} \\
\hline 10.25 & 10.25 & $r \leq 2$ & 9.89 & 9.89 \\
\hline 87.99 & 84.69 & $r \leq 1$ & 22.78 & 12.89 \\
\hline 100.52 & 89.19 & $\mathrm{r}=0$ & 46.79 & 24.01 \\
\hline \multicolumn{5}{|c|}{ all countries: $1974: 2-1993: 2 \mathrm{~d}$} \\
\hline 22.36 & 22.36 & $\mathrm{r} \leq 7$ & 4.94 & 4.94 \\
\hline 30.61 & 29.00 & $r \leq 6$ & 16.13 & 11.18 \\
\hline 58.89 & 47.46 & $r \leq 5$ & 29.77 & 13.64 \\
\hline 119.58 & 94.60 & $r \leq 4$ & 48.14 & 18.37 \\
\hline 173.57 & 127.60 & $r \leq 3$ & 72.40 & 24.27 \\
\hline 224.74 & 155.59 & $r \leq 2$ & 100.23 & 27.83 \\
\hline 255.62 & 159.69 & $r \leq 1$ & 160.56 & 60.33 \\
\hline 294.25 & 164.78 & $\mathrm{r}=0$ & 224.02 & 63.46 \\
\hline \multicolumn{5}{|c|}{ all countries: $1982: 1-1993: 2 \mathrm{e}$} \\
\hline 3.85 & 3.85 & $r \leq 6$ & 0.76 & 0.76 \\
\hline 15.17 & 13.91 & $r \leq 5$ & 5.31 & 4.55 \\
\hline 29.18 & 20.73 & $r \leq 4$ & 14.58 & 9.27 \\
\hline 47.58 & 27.22 & $r \leq 3$ & 34.16 & 19.58 \\
\hline 69.50 & 33.85 & $r \leq 2$ & 59.31 & 25.15 \\
\hline 95.90 & 40.30 & $r \leq 1$ & 95.41 & 36.11 \\
\hline 127.12 & 46.73 & $r=0$ & $143.11^{\mathrm{f}}$ & $47.70^{\mathrm{f}}$ \\
\hline
\end{tabular}


a All critical values are calculated via Monte Carlo with 10,000 replications for the appropriate sample size and $\lambda$ combination in each case. For $\lambda$ combinations see Table 1. b Indonesia, Kuwait, Libya, Saudi Arabia, and Venezuela. c Kuwait, Saudi Arabia and U.A.E. d Algeria, Gabon, Indonesia, Libya, Nigeria, Saudi Arabia, U.A.E. and Venezuela. e Algeria, Gabon, Indonesia, Iran, Saudi Arabia, U.A.E. and Venezuela. $\mathrm{f}$ The null hypothesis of no cointegration is rejected at the $5 \%$ significance level. 
Table 4a- Causality test results (with OPEC). ${ }^{\text {a }}$

\begin{tabular}{|c|c|c|c|c|}
\hline & \multicolumn{2}{|c|}{ Bivariate } & \multicolumn{2}{|c|}{ Trivariate } \\
\hline & Granger & GMD & Granger & GMD \\
\hline \multicolumn{5}{|c|}{ 1965:1-1993:2 } \\
\hline OPEC --> Price & 0.188 & 0.449 & 0.165 & 0.459 \\
\hline Price --> OPEC & 0.993 & 0.918 & 0.995 & 0.658 \\
\hline Non-OPEC --> Price & 0.743 & 0.733 & 0.783 & 0.647 \\
\hline Price --> Non-OPEC & 0.807 & 0.967 & 0.911 & 0.960 \\
\hline \multicolumn{5}{|c|}{ 1965:1-1973:9 } \\
\hline OPEC --> Price & 0.901 & 0.611 & 0.490 & 0.631 \\
\hline Price --> OPEC & 0.604 & 0.477 & 0.566 & 0.180 \\
\hline Non-OPEC --> Price & 0.498 & 0.660 & 0.797 & 0.611 \\
\hline Price --> Non-OPEC & 0.257 & 0.289 & 0.550 & 0.770 \\
\hline \multicolumn{5}{|c|}{ 1974:2-1993:2 } \\
\hline OPEC --> Price & 0.143 & 0.328 & 0.129 & 0.350 \\
\hline Price --> OPEC & 0.989 & 0.851 & 0.987 & 0.839 \\
\hline Non-OPEC --> Price & 0.821 & 0.828 & 0.724 & 0.796 \\
\hline Price --> Non-OPEC & 0.791 & 0.893 & 0.800 & 0.936 \\
\hline \multicolumn{5}{|c|}{ 1982:1-1993:2 } \\
\hline OPEC --> Price & 0.024 & 0.026 & 0.020 & 0.033 \\
\hline Price --> OPEC & 0.417 & 0.709 & 0.583 & 0.612 \\
\hline Non-OPEC --> Price & 0.770 & 0.675 & 0.614 & 0.822 \\
\hline Price --> Non-OPEC & 0.177 & 0.123 & 0.172 & 0.217 \\
\hline
\end{tabular}

a Reported are p-values for joint significance tests. 
Table 4b- Causality test results (with Saudi Arabia). ${ }^{\text {a }}$

\begin{tabular}{|c|c|c|c|c|}
\hline & \multicolumn{2}{|c|}{ Bivariate } & \multicolumn{2}{|c|}{ Trivariate } \\
\hline & Granger & GMD & Granger & GMD \\
\hline \multicolumn{5}{|c|}{ 1965:1-1993:2 } \\
\hline Saudi Arabia --> Price & 0.244 & 0.632 & 0.523 & 0.187 \\
\hline Price --> Saudi Arabia & 0.930 & 0.992 & 0.740 & 0.935 \\
\hline Non-OPEC --> Price & - & - & 0.550 & 0.697 \\
\hline Price --> Non-OPEC & - & - & 0.828 & 0.799 \\
\hline \multicolumn{5}{|c|}{ 1965:1-1973:9 } \\
\hline Saudi Arabia --> Price & 0.690 & 0.463 & 0.757 & 0.990 \\
\hline Price --> Saudi Arabia & 0.955 & 0.967 & 0.979 & 0.992 \\
\hline Non-OPEC --> Price & - & - & 0.530 & 0.714 \\
\hline Price --> Non-OPEC & - & - & 0.267 & 0.296 \\
\hline \multicolumn{5}{|c|}{ 1974:2-1993:2 } \\
\hline Saudi Arabia --> Price & 0.364 & 0.211 & 0.387 & 0.312 \\
\hline Price --> Saudi Arabia & 0.563 & 0.908 & 0.814 & 0.897 \\
\hline Non-OPEC --> Price & - & - & 0.795 & 0.498 \\
\hline Price --> Non-OPEC & - & -- & 0.674 & 0.907 \\
\hline \multicolumn{5}{|c|}{ 1982:1-1993:2 } \\
\hline Saudi Arabia --> Price & 0.475 & 0.601 & 0.466 & 0.751 \\
\hline Price --> Saudi Arabia & 0.809 & 0.847 & 0.880 & 0.920 \\
\hline Non-OPEC --> Price & - & - & 0.739 & 0.814 \\
\hline Price --> Non-OPEC & - & - & 0.295 & 0.042 \\
\hline
\end{tabular}

a Reported are p-values for joint significance tests. 
Table 2a- Bivariate cointegration test results (vs OPEC) a

\begin{tabular}{|c|c|c|c|c|c|c|}
\hline & \multicolumn{2}{|c|}{$1965: 1-1993: 2$} & \multicolumn{2}{|c|}{$1974: 2-1993: 2$} & \multicolumn{2}{|c|}{ 1982:1-1993:2 } \\
\hline & Test statistic ${ }^{b}$ & $\begin{array}{c}\text { Critical values at } \\
1 \% \text { and } 5 \%\end{array}$ & Test statistic ${ }^{b}$ & $\begin{array}{c}\text { Critical values at } \\
1 \% \text { and } 5 \%\end{array}$ & Test statistic ${ }^{b}$ & $\begin{array}{c}\text { Critical values at } \\
1 \% \text { and } 5 \% \\
\end{array}$ \\
\hline Algeria & -- & -- & $-5.26[0]$ & $-5.00,-4.56$ & $-3.19[0]$ & $-4.39,-3.79$ \\
\hline Gabon & -- & -- & $-4.12[0]$ & $-5.11,-4.56$ & $-3.83[1]$ & $-4.86,-4.30$ \\
\hline Indonesia & $-4.13[9]$ & $-5.90,-5.31$ & $-4.27[3]$ & $-5.20,-4.62$ & $-2.39[2]$ & $-4.39,-3.79$ \\
\hline Iran & -- & -- & -- & -- & $-3.39[2]$ & $-4.39,-3.79$ \\
\hline Kuwait & $-6.33[0]$ & $-5.91,-5.35$ & -- & -- & -- & -- \\
\hline Libya & $-6.12[0]$ & $-6.26,-5.65$ & $-5.10[0]$ & $-5.36,-4.75$ & -- & -- \\
\hline Nigeria & $-4.55[11]$ & $-5.71,-5.13$ & $-7.50[0]$ & $-5.26,-4.64$ & -- & -- \\
\hline Saudi Arabia & $-4.28[0]$ & $-5.97,-5.41$ & $-3.53[0]$ & $-5.73,-5.17$ & $-2.61[4]$ & $-4.64,-4.06$ \\
\hline U. A. E. & $-5.95[0]$ & $-5.24,-4.64$ & $-6.86[0]$ & $-4.92,-4.31$ & $-5.64 \quad[1]$ & $-4.64,-4.06$ \\
\hline Venezuela & $-5.74[0]$ & $-5.88,-5.31$ & $-4.41[0]$ & $-4.92,-4.34$ & $-4.32[0]$ & $-4.54,-4.02$ \\
\hline
\end{tabular}

\footnotetext{
a For $\lambda$ combinations see Table 1. Critical values are calculated via Monte Carlo for 500 observations with 10,000 replications.
}

$\mathrm{b}$ Numbers in squared brackets are the numbers of lagged differences used in augmenting the estimated equation. 
Table 2b- Bivariate cointegration test results (vs Saudi Arabia) a

\begin{tabular}{|c|c|c|c|c|c|c|}
\hline & \multicolumn{2}{|c|}{ 1965:1-1993:2 } & \multicolumn{2}{|c|}{$1974: 2-1993: 2$} & \multicolumn{2}{|c|}{$1982: 1-1993: 2$} \\
\hline & Test statistic ${ }^{b}$ & $\begin{array}{c}\text { Critical values at } \\
1 \% \text { and } 5 \% \\
\end{array}$ & Test statistic $b$ & $\begin{array}{c}\text { Critical values at } \\
1 \% \text { and } 5 \% \\
\end{array}$ & Test statistic $b$ & $\begin{array}{c}\text { Critical values at } \\
1 \% \text { and } 5 \%\end{array}$ \\
\hline Algeria & -- & -- & $-5.42[0]$ & $-5.10,-4.51$ & $-3.16[1]$ & $-4.39,-3.79$ \\
\hline Gabon & -- & -- & $-4.08[0]$ & $-5.13,-4.60$ & $-3.75[1]$ & $-4.86,-4.30$ \\
\hline Indonesia & $-3.84[13]$ & $-5.93,-5.31$ & $-2.89[9]$ & $-5.30,-4.70$ & $-2.77[2]$ & $-4.39,-3.79$ \\
\hline Iran & -- & -- & -- & -- & $-2.71[3]$ & $-4.39,-3.79$ \\
\hline Kuwait & $-4.53 \quad[1]$ & $-5.96,-5.37$ & -- & -- & -- & -- \\
\hline Libya & $-5.16[1]$ & $-6.26,-5.67$ & $-5.16[0]$ & $-5.39,-4.84$ & -- & -- \\
\hline Nigeria & $-7.90[1]$ & $-5.71,-5.08$ & $-6.77[1]$ & $-5.24,-4.64$ & -- & -- \\
\hline U. A. E. & $-4.87[1]$ & $-5.16,-4.61$ & $-3.90[0]$ & $-4.82,-4.23$ & $-4.70[1]$ & $-4.64,-4.06$ \\
\hline Venezuela & $-5.08[1]$ & $-5.88,-5.29$ & $-3.57 \quad[2]$ & $-4.90,-4.32$ & $-4.37[0]$ & $-4.54,-4.02$ \\
\hline
\end{tabular}

a, b See Table 2a. 


\section{Figure 1- Price of Oil}

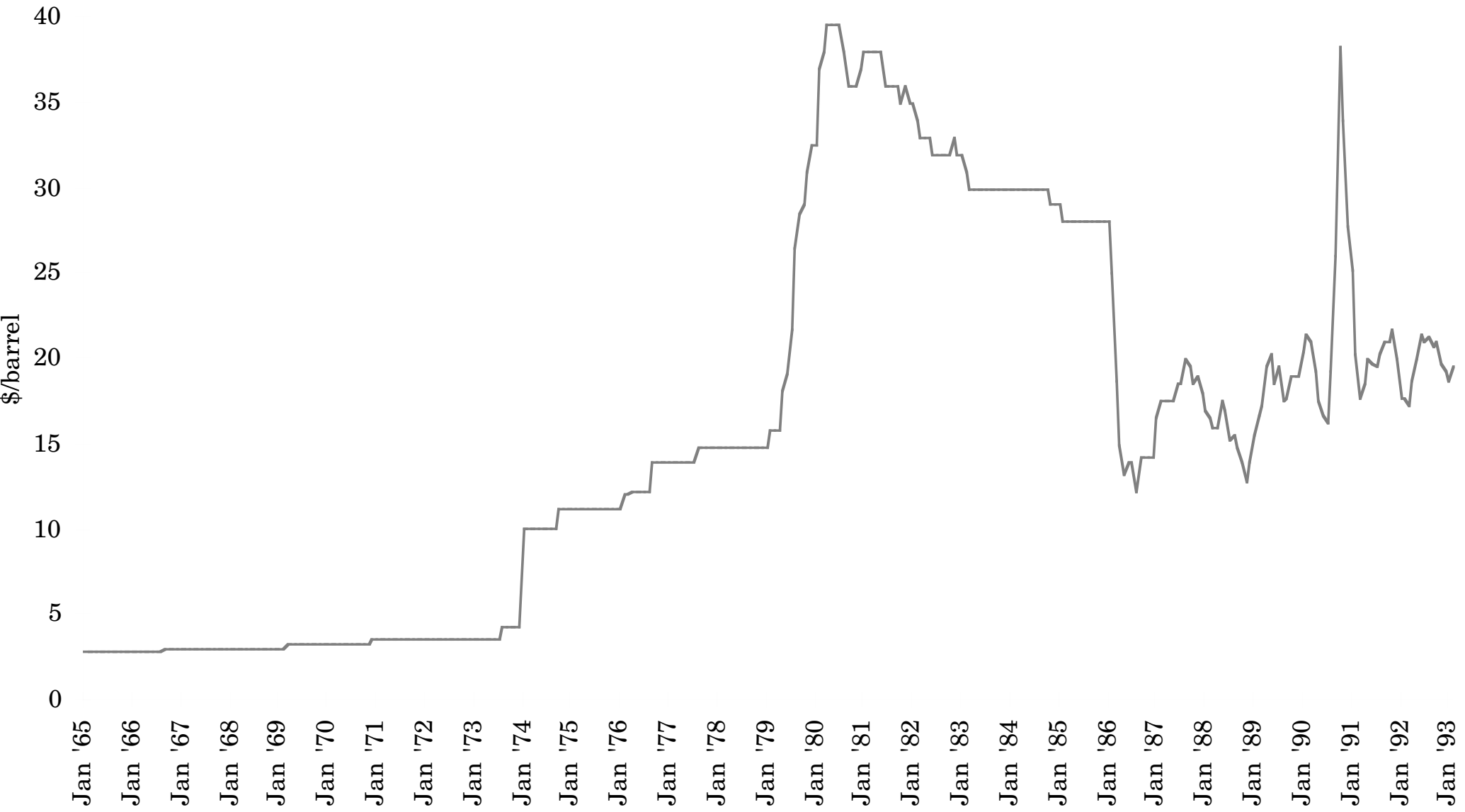




\section{Figure 2- Oil Production}

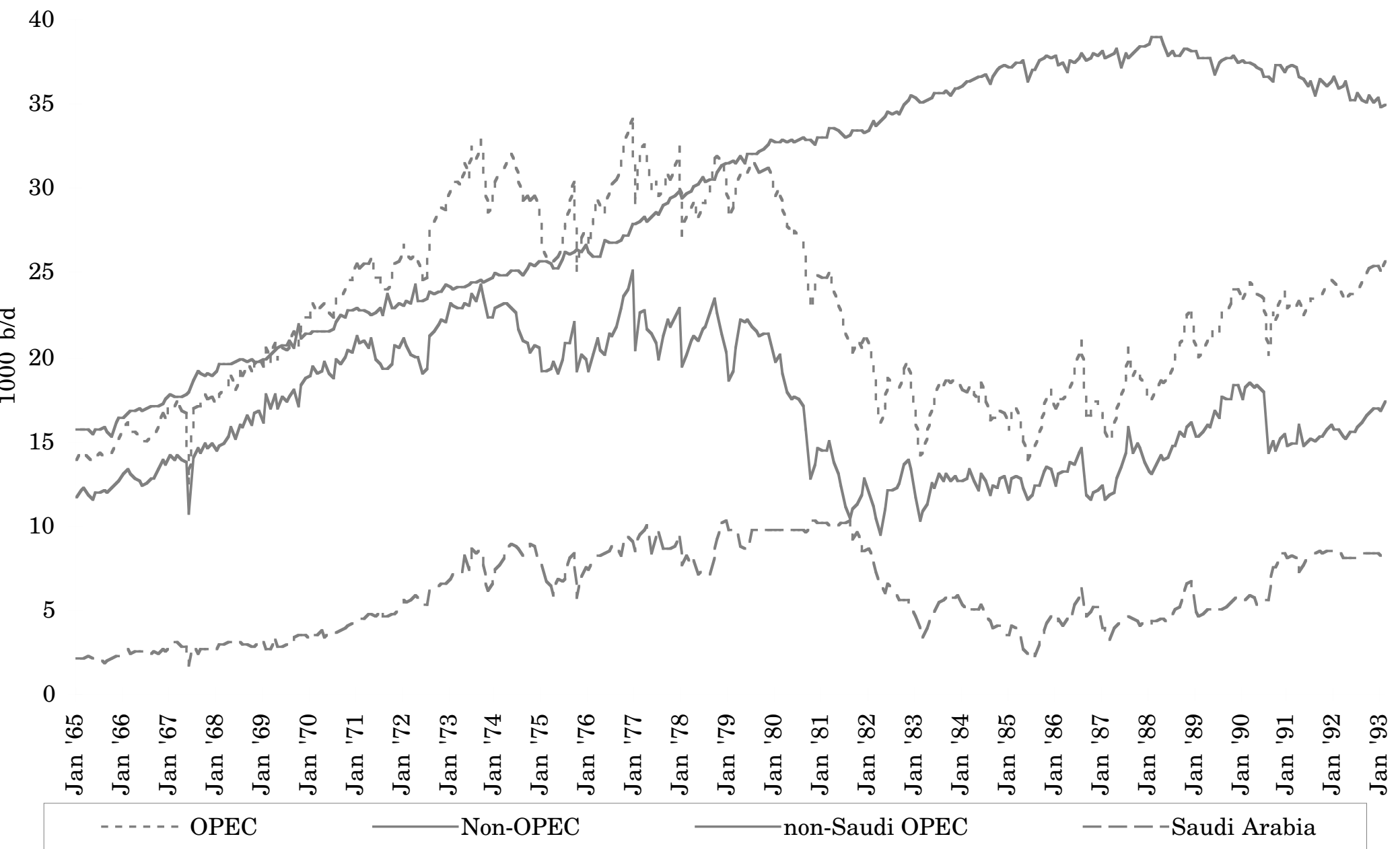




\section{Figure 3-Realised OPEC Production Shares}

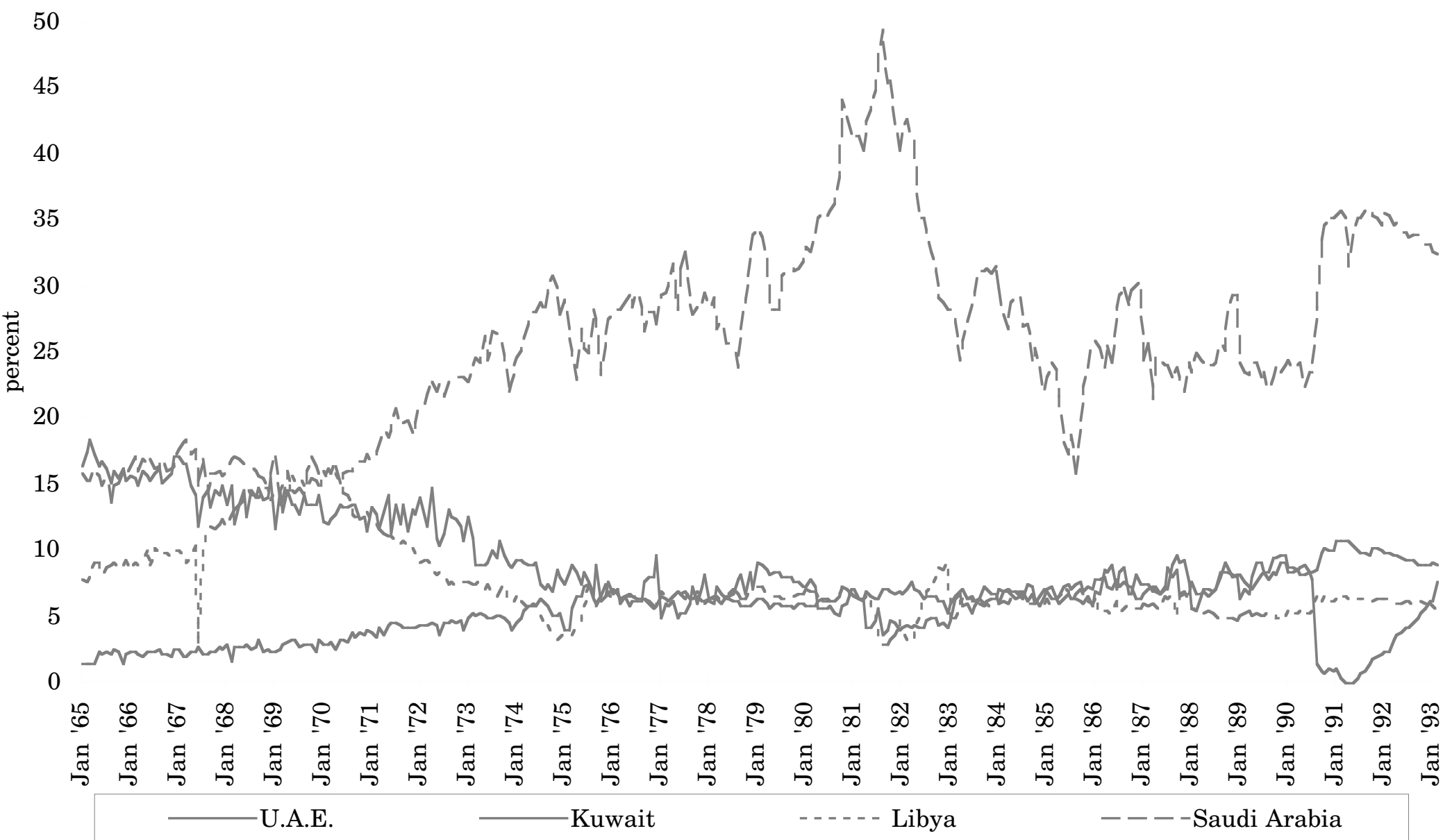




\section{Figure 3 (cont'd)}

35

30

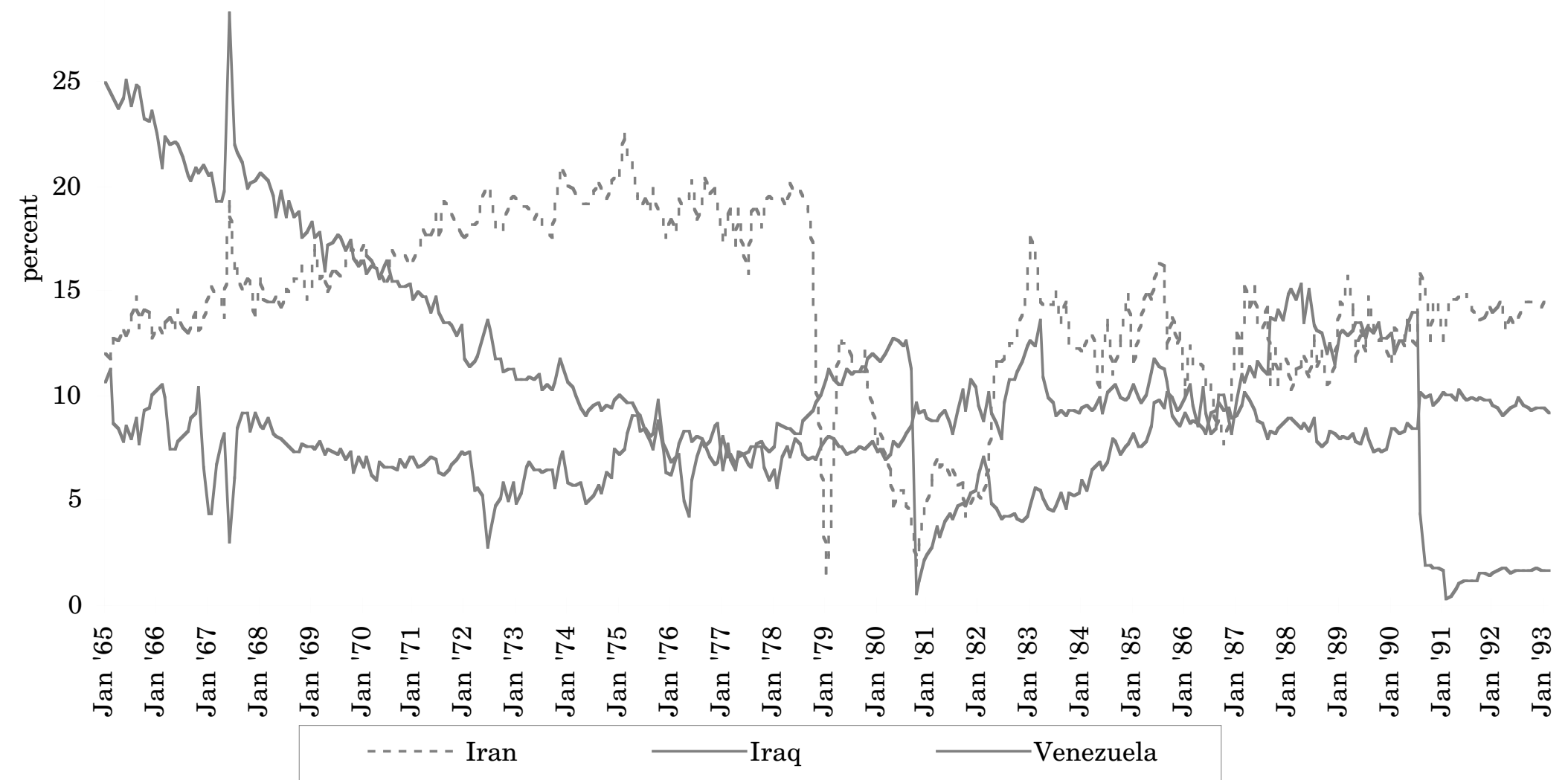




\section{Figure 3 (cont'd)}

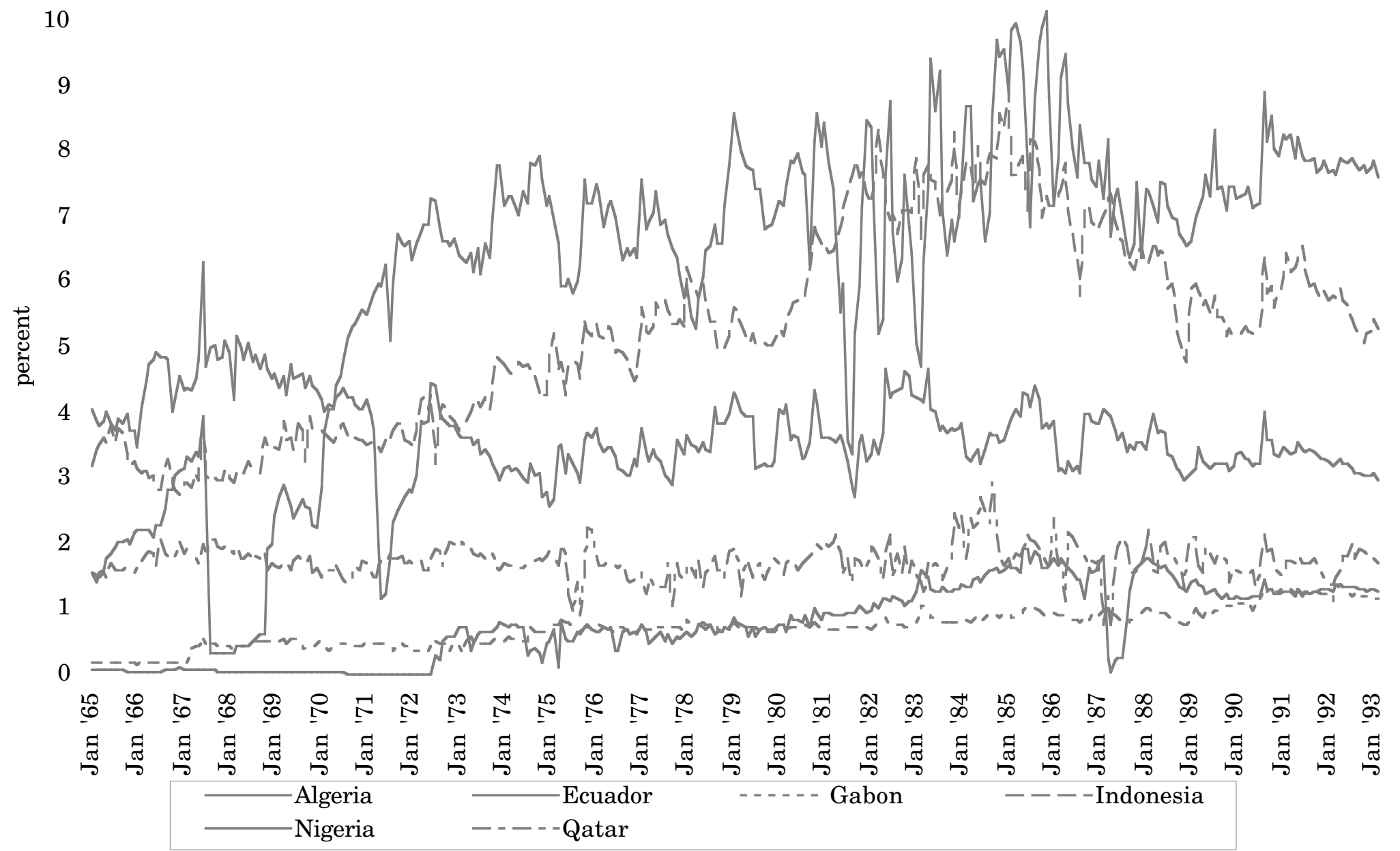

